\title{
Dependence of ZnO-based dye-sensitized solar cell characteristics on the layer deposition method
}

\author{
ANCA DUMBRAVA ${ }^{1, *}$, GABRIEL PRODAN ${ }^{2}$, ADRIAN GEORGESCU ${ }^{2}$ and FLORIN MOSCALU ${ }^{2}$ \\ ${ }^{1}$ Department of Chemistry and Chemical Engineering, Ovidius University of Constanta, Constanta 900527, Romania \\ ${ }^{2}$ Department of Physics, Ovidius University of Constanta, Constanta 900527, Romania
}

MS received 18 January 2014

\begin{abstract}
The selection of a proper method for the semiconductor layer deposition is an important requirement towards a high efficiency for dye-sensitized solar cells (DSSCs). We compared three techniques for deposition of the semiconductor thin layer in $\mathrm{ZnO}$-based DSSCs, in order to determine the dependence between the deposition method, the ZnO film properties and finally the DSSCs characteristics. For this purpose, we varied the method used for deposition of the semiconductor film and we replaced $\mathrm{ZnO}$ with Al-doped $\mathrm{ZnO}$. The nanostructured films morphology was analysed by transmission electron microscopy, high-resolution transmission electron microscopy and selected area electron diffraction. The optical properties were examined by UV-visible spectroscopy and the bandgap energies were calculated using the Tauc equation. The higher fill factor value was registered for DSSCs based on the $\mathrm{ZnO}$ film obtained by electrochemical method, but the higher efficiency was registered for doctorblading method.
\end{abstract}

Keywords. Dye-sensitized solar cells; zinc oxide; transmission electron microscopy; optical properties; Tauc plot.

\section{Introduction}

In the current energy perspective, the solar energy seems to be a good alternative for the fossil fuels, but the use of solar energy remains yet a challenge and also an aspiration for the scientists. In 1991, O'Regan and Grätzel ${ }^{1}$ reported for the first time about dye-sensitized solar cells (DSSCs, or Grätzel cells), which mimic the natural photosynthesis. In the next 30 years, the DSSCs were extensively studied, the Grätzel cells being considered a low cost and promising solution to solve the energy problem. ${ }^{2}$

The DSSC realizes the optical absorption and the charge separation processes by the association of a sensitizer, as light-absorbing material, with a wide bandgap semiconductor of nanaocrystalline morphology. ${ }^{3}$ Thus, the actual DSSC contains broadly five components: (i) a mechanical support coated with transparent conductive oxides; (ii) the semiconductor film, usually $\mathrm{TiO}_{2}$; (iii) a sensitizer adsorbed onto the surface of the semiconductor; (iv) an electrolyte containing a redox mediator and (v) a counter electrode capable of regenerating the redox mediator like platinum. ${ }^{1,2}$ The heart of the system seems to be the mesoporous oxide layer composed of nanometre-sized particles that have been sintered together to allow for electronic conduction to take place. The material of choice has been $\mathrm{TiO}_{2}$ (anatase), although alternative wide bandgap oxides such as $\mathrm{ZnO}$ and $\mathrm{Nb}_{2} \mathrm{O}_{5}$ have also been investigated. $^{3}$

*Author for correspondence (adumbrava@univ-ovidius.ro)
Because of its properties, like piezoelectricity, chemical stability, biocompatibility, optical transparency in the visible region, high voltage-current nonlinearity etc., ${ }^{4,5} \mathrm{ZnO}$ is an attractive material for a broad range of electronic, optical and piezoelectric applications. ${ }^{6} \mathrm{ZnO}$, crystallized into two main forms (i.e., hexagonal wurtzite and cubic zinc blende), belongs to the II-VI semiconductor group; in the wurtzite phase, $\mathrm{ZnO}$ has a wide bandgap $\left(E_{\mathrm{g}} \sim 3.3 \mathrm{eV}\right.$ at $300 \mathrm{~K}$ ), which corresponds to emission in the UV region, and a large exciton binding energy of $60 \mathrm{meV}^{7,8}$ As a direct and large bandgap material, $\mathrm{ZnO}$ is attracting much attention for a variety of electronic and optoelectronic applications. Advantages associated with a large bandgap include hightemperature and high-power operation, lower noise generation, higher breakdown voltages and ability to sustain large electric fields. ${ }^{9}$

Historically, $\mathrm{ZnO}$ was one of the first semiconductors used in DSSCs. The bandgap and conduction band edge of $\mathrm{ZnO}$ are similar to those of $\mathrm{TiO}_{2}$ (anatase), but the chemical stability of $\mathrm{ZnO}$ is rather poor compared with that of $\mathrm{TiO}_{2}$; thus, it dissolves under both acidic and basic conditions. On the other side, $\mathrm{ZnO}$ has higher electron mobility than $\mathrm{TiO}_{2}$, which should favour electron transport. The researchers' interest in $\mathrm{ZnO}$ for DSSCs can be mainly attributed to the relative ease of synthesizing highly crystalline $\mathrm{ZnO}$ (in the wurtzite structure) with different morphologies, such as nanoparticles, nanowires, nanorods, nanotubes, tetrapods, nanoflowers, nanosheets and branched nanostructures. ${ }^{10,11}$ Al-doped $\mathrm{ZnO}$ (AZO) films have got potential applications in solar cells, solid-state display devices, optical coatings, 
heaters, defrosters, chemical sensors, etc. ${ }^{12,13}$ AZO is attractive for photovoltaic applications due to $\mathrm{ZnO}$ conductivity when doped with aluminium and transparency to the visible range of sunlight, i.e., minimized optical and electrical loss. ${ }^{14}$

Several methods on the synthesis of various shaped $\mathrm{ZnO}$ nanostructured thin films are developed; for example, $\mathrm{ZnO}$ microrods were obtained by using spray pyrolysis, $\mathrm{ZnO}$ nanocomposite films deposited onto glass substrates were obtained by magnetron sputtering in different atmospheres, $\mathrm{ZnO}$ microrods were deposited by the hydrothermal method, $\mathrm{ZnO}$ nanofibres were deposited by electrospinning technique, and so on. ${ }^{5}$ Among the known methods, the chemical bath deposition remains one of the most used for the deposition of thin films, but the properties of resulted $\mathrm{ZnO}$ films are influenced by the substrate, differences in the morphology can be attributed to different substrates used, because nucleation and growth process in the chemical bath deposition depends on the nature of substrate. ${ }^{15}$

In the most common method, the mesoporous $\mathrm{ZnO}$ electrodes for DSSCs can be prepared from a paste containing $\mathrm{ZnO}$ nanoparticles, followed by doctor-blading or screen printing onto FTO substrates and sintering. ${ }^{11}$ The $\mathrm{ZnO}$ nanoparticles may be synthesized by a large variety of methods. ${ }^{9,16,17}$

The aim of our study is to evidence the influence of the deposition method on the semiconductor layer properties, and accordingly on the DSSCs characteristics, focusing on $\mathrm{ZnO}$ films. For this purpose, we prepared $\mathrm{ZnO}$ thin films using three different methods, i.e., doctor-blading, electrolysis and spin coating; which also used $\mathrm{Al}$-doped $\mathrm{ZnO}(6 \% \mathrm{Al})$ to emphasize the influence of semiconductor composition. The morphology of obtained films was analysed by transmission electron microscopy (TEM), high-resolution transmission electron microscopy (HRTEM), and selected area electron diffraction (SAED); the optical properties were studied by UV-vis spectroscopy and the bandgap energy values were determined using the Tauc equation. The characteristics of ZnO-based DSSCs were correlated with the morphologies, optical and electrical properties.

\section{Experimental}

\subsection{The deposition of thin films}

All the reagents were purchased from commercial sources and used as received.

The thin films were deposited on conductive glass substrate, which consists of a soda lime glass sheet of $2.2 \mathrm{~mm}$ thickness, with a conductive layer of F-doped $\mathrm{SnO}_{2}$, having sheet resistance of $15 \Omega \mathrm{cm}^{-2}$ (Solaronix) and an optical transmission greater than or equal to $80 \%$, in the $400-700 \mathrm{~nm}$ region.

The $\mathrm{ZnO}$ thin films were obtained as follows:

(i) Doctor-blading method (ZnO 1), using aluminiumdoped $\mathrm{ZnO}$ (AZO) nanopowder. Commercial $\mathrm{ZnO}$ doped with 6\% Al nanopowder (Sigma-Aldrich, $1 \mathrm{~g}$ ) was dispersed in a solution containing acetic acid (Sigma-Aldrich, $0.25 \mathrm{ml}$ ), ethanol (Sigma-Aldrich, $16.75 \mathrm{ml})$ and deionized water $(8 \mathrm{ml})$. The nanocrystalline AZO pastes thus obtained were coated on FTO conducting glass sheets by the doctor-blading technique. The coated films were initially dried at $90^{\circ} \mathrm{C}$ for $30 \mathrm{~min}$ and then heated at $450^{\circ} \mathrm{C}$ for $10 \mathrm{~min}$ in air. ${ }^{18}$

(ii) Electrolytic method (ZnO 2). The ITO substrate was immersed in a $0.5 \mathrm{M}$ zinc acetate (Sigma-Aldrich), and an electric potential of $2.5 \mathrm{~V}$ was applied to the electrolytic cell, consisting in the ITO substrate as cathode and a carbon rod as anode. The deposition time was about $5 \mathrm{~min}$. The substrate was subsequently heattreated at $500^{\circ} \mathrm{C}$ for $30 \mathrm{~min}$, to obtain $\mathrm{ZnO}$ and to improve the crystallinity of the film of $\mathrm{ZnO}$ nanoparticles. The method was modified compared with that reported in literature. ${ }^{19}$

(iii) Spin coating method ( $\mathrm{ZnO} 3, \mathbf{Z n O} 4)$. A solution of $2.19 \mathrm{~g}(10 \mathrm{mmol}) \mathrm{Zn}\left(\mathrm{CH}_{3} \mathrm{COO}\right)_{2} \cdot 2 \mathrm{H}_{2} \mathrm{O}$ (SigmaAldrich) in $10 \mathrm{ml}$ 2-propanol (Sigma Aldrich) was added to diethanolamine $\left(\mathrm{C}_{4} \mathrm{H}_{11} \mathrm{NO}_{2}\right.$, Sigma Aldrich) $(1.05 \mathrm{~g}, 10 \mathrm{mmol})$. The mixture was stirred by a magnetic stirrer at $50^{\circ} \mathrm{C}$ for 10 min until a clear solution formed. Afterwards, water ( $5 \mathrm{ml}$ ) for $\mathbf{Z n O ~ 3}$, or ethanol $(5 \mathrm{ml})$ for $\mathbf{Z n O ~ 4}$, was slowly added under stirring for $30 \mathrm{~min}$ in order to keep the mixture from precipitation. Deposition was carried out onto FTO conducting glass, in air, at three steps with different spinning speeds, which are 2000 revolutions per minute (r.p.m.) for $30 \mathrm{~s}, 4000$ r.p.m. for $30 \mathrm{~s}$ and 6000 r.p.m. for $60 \mathrm{~s}$. A precursor film on the substrate was formed following the spin coating process. The film was then dried at $250^{\circ} \mathrm{C}$ for $1 \mathrm{~min}$ on a hot plate. The preheat treatment temperature of $250^{\circ} \mathrm{C}$ is required for the complete evaporation of organics and the initiation of formation and crystallization of the $\mathrm{ZnO}$ film. Spinning-drying cycle was repeated for 10 times in order to get more homogeneous film and desired film thickness. After the deposition of last coating layer, the resulting film was annealed in air at $500^{\circ} \mathrm{C}$ for $1 \mathrm{~h} .{ }^{5,20} \mathrm{~A}$ single wafer spin processor, model WS-400-6NPP-LITE, from Laurell Technologies Corporation was used.

\subsection{The fabrication of DSSCs}

The $\mathrm{ZnO}$ plates were immersed in $0.3 \mathrm{mM}$ N719 dye (Solaronix) solution in anhydrous ethanol (Sigma-Aldrich) by soaking for $2 \mathrm{~h}$ at $70^{\circ} \mathrm{C}$. The non-adsorbed dye were washed away with ethanol until the rinse liquid was colourless and then dried at $80^{\circ} \mathrm{C}$ for $30 \mathrm{~min}$.

Platinum counter electrodes were prepared by spreading a few drops of $5 \mathrm{mM} \mathrm{H}_{2}\left[\mathrm{PtCl}_{6}\right]$. $6 \mathrm{H}_{2} \mathrm{O}$ solution in 2-propanol (Solaronix) on the FTO glass, followed by drying at $100^{\circ} \mathrm{C}$ for $10 \mathrm{~min}$ and then at $385^{\circ} \mathrm{C}$ for $30 \mathrm{~min}^{21}$

DSSCs were assembled following the procedure described in the literature, ${ }^{22}$ the catalyst-coated counter electrode being placed on the top, so that the conductive side of the counter 
electrode faced the $\mathrm{ZnO}$ film. The iodide electrolyte solution (Iodolyte TG-50, $50 \mathrm{mM}$ of tri-iodide in Tetraglyme, from Solaronix) was placed at the edges of the plates. The liquid was drawn into the space between the electrodes by capillary action. Two binder clips were used to hold the electrodes together.

The standard DSSCs prepared with $\mathrm{TiO}_{2}$ nanopowders and N719 dye, using the photoanodes pre- and post-treated with $\mathrm{TiCl}_{4}$ (control cell), lead to a solar energy conversion efficiency of $2.26 \% .^{23-25}$

\subsection{Characterization and measurements}

The TEM, HRTEM and SAED investigations of $\mathrm{ZnO}$ films were performed on a Philips CM 120 ST transmission electron microscope operated at $100 \mathrm{kV}$, with $2 \AA$ resolution. The samples were mechanically removed from the plates and pestled with an agate mortar. The specimens of TEM samples were prepared by ultrasonic dispersion of pestled samples in anhydrous ethylic alcohol (Sigma-Aldrich) and then placing drops of the suspension on a copper microgrid with carbon film and immediately evaporating the solvent.

The UV-vis absorption spectra were recorded in the range 220-850 nm, on a Jasco V550 spectrophotometer, in an integrating sphere.

The electro-optical parameters of the DSSCs, the short circuit current $\left(I_{\mathrm{SC}}\right)$, the open circuit voltage $\left(V_{\mathrm{OC}}\right)$, the fill factor $(\mathrm{FF})$ and the photovoltaic conversion efficiency $(\eta)$ were measured under AM 1.5 G standard conditions (1000 $\mathrm{W} \mathrm{m}{ }^{-2}$ ) at $25^{\circ} \mathrm{C}$, using a homemade class A small area solar simulator. ${ }^{26}$ The cell surface was exposed to light through a circular slit of $10 \mathrm{~mm}$ diameter, resulting in a useful area of about $0.785 \mathrm{~cm}^{2}$. The current and voltage values were measured using two digital bench multimetres (Mastech MS8050) and a decadic resistance box. All measurements were made at intervals of $45 \mathrm{~s}$, allowing for each reading to stabilize.

\section{Results and discussion}

\subsection{Transmission electron microscopy and electron diffraction}

The investigation and controlling of sizes and shapes of inorganic nanomaterials are important, because these parameters represent key elements that determine their electrical and optical properties. ${ }^{27}$

The $\mathrm{ZnO}$ particles size and morphology were investigated by the TEM technique. Evaluation of mean diameter was performed using a semi-automated algorithm implemented in the analysis software. Mean diameter was calculated as arithmetic mean of all diameters measured on particles at angles that varies with $15^{\circ}$ steps. The final mean diameter was approximated assuming a lognormal distribution of resulted diameters. Experimental diameter measured from TEM micrograph was fitted with function given by

$$
y=y_{\mathrm{o}}+A e^{-\left(\ln ^{2}\left(x / x_{\mathrm{c}}\right)\right) / 2 w^{2}}
$$

where $A$ is an arbitrary constant related to particle number, $x_{\mathrm{c}}$ represents the distribution maximum and $w$ the strong correlated with particle diameter dispersion.

The bright field TEM (BF-TEM) images and the fitted curve of evaluated diameters using function for lognormal distribution for $\mathrm{ZnO}$ particles are presented in figure 1 .

As we can see in figure 1a, the particles dimension for ZnO 1 film remains in the nanorange. The diameters of AZO particles in the powder are below $50 \mathrm{~nm}$, as the producer labelled. The transformation of nanopowder in thin film, by the doctor-blading method, conducted to a mean diameter of $24 \mathrm{~nm}$ (calculated value of $23.98 \mathrm{~nm}$ ) and most particles have diameter under $50 \mathrm{~nm}$. The TEM also revealed a small fraction of particles having diameter in 50-70 nm range, probably because of the synthesis of aggregates during the procedure of making the paste and the film. However, the particles are uniform and their dimensions are kept approximately constant, meaning that doctor blading is a proper method to make nanostructured thin films by using nanopowders.

The results for particles that compose the layers obtained by electrolysis (ZnO 2) are unexpectedly good, having in view that the method is accessible, easy and cheap. As it is shown in figure $1 \mathrm{~b}$, the mean diameter of particles is around $39 \mathrm{~nm}$ (calculated value of $39.29 \mathrm{~nm}$ ), the particles are uniform.

Figure 2 shows the SAED patterns of $\mathrm{ZnO}$ crystals. The diffraction rings composed of dots show that the particles are well crystallized and can be indexed to (100), (002), (101), (102), (110), (103), (200), (112), (202), (104) and (203) for ZnO 1, and (100), (002), (101), (102), (110), (103), (200), (202), (104) and (203) for ZnO 2, which is in accordance with similar peaks founded in crystallography database (JCPDS 36-1451) for the XRD pattern of wurtzite $\mathrm{ZnO}$ ( $P 6_{3} m c$ group in the Hermann-Mauguin notation). ${ }^{8}$

The wurtzite structure has a hexagonal unit cell with two lattice parameters $a$ and $c$ in the ratio of $c / a=\sqrt{8 / 3}=1.633$ (in an ideal wurtzite structure) and belongs to the space group $C_{6 \mathrm{v}}^{4}$ in the Schoeflies notation and $P 6_{3} m c$ in the HermannMauguin notation. In a real $\mathrm{ZnO}$ crystal, the wurtzite structure deviates from the ideal arrangement, by changing the $c / a$ ratio and the experimentally observed $c / a$ ratios are smaller than ideal. The lattice constants mostly range from 3.2475 to $3.2501 \AA$ for the $a$-parameter and from 5.2042 to $5.2075 \AA$ for the $c$-parameter. ${ }^{9}$

The calculated values of lattice parameters ${ }^{28}$ for studied $\mathrm{ZnO}$ samples (table 1) are very similar and close to those determined for ideal structure. Although the values for $\mathbf{Z n O}$ 2 lattice parameters are very similar to those reported for wurtzite structure, the values of lattice parameters for $\mathbf{Z n O} 1$ are smaller and the lattice seems to be compressed for hosting smaller Al ions. 

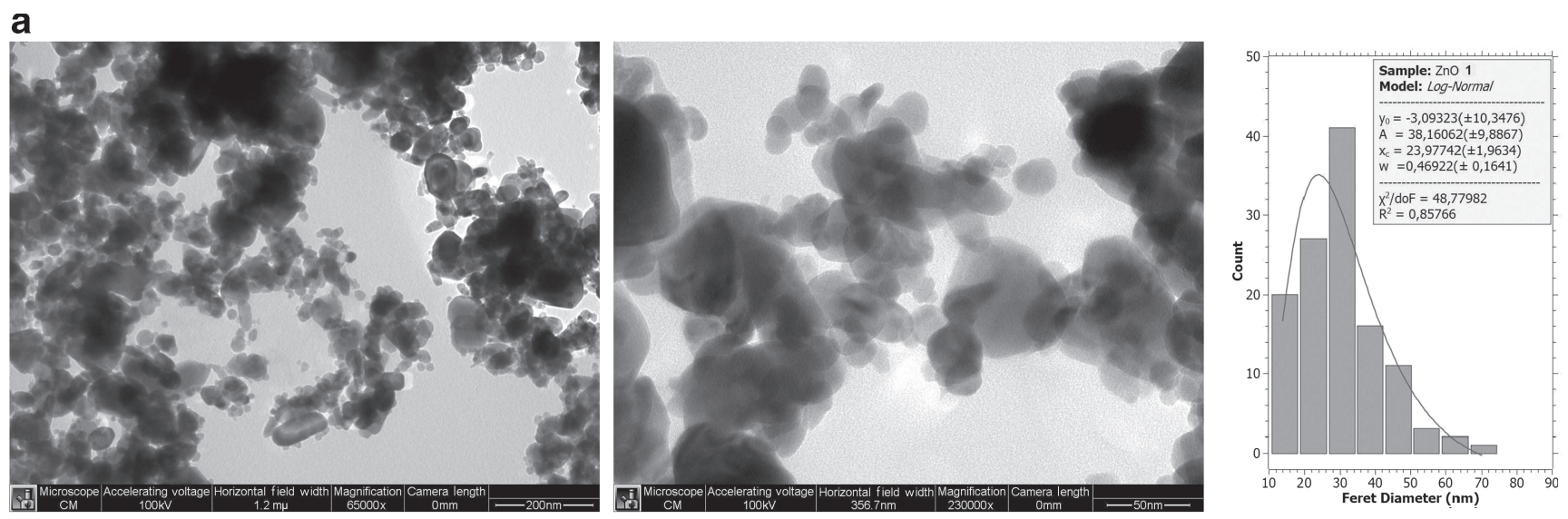

b
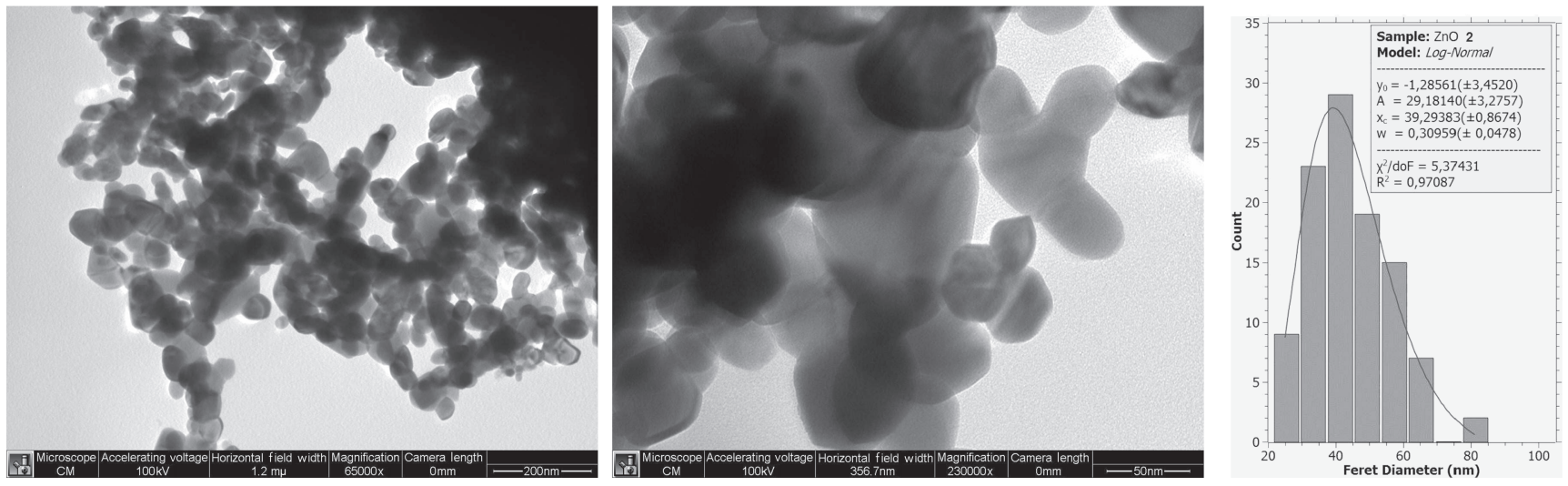

Figure 1. TEM images, mean particle size and particle distribution for (a) $\mathbf{Z n O} 1$ and (b) $\mathbf{Z n O} 2$.

The $\mathrm{ZnO}$ transparent films obtained using the spin coating method ( $\mathrm{ZnO} 3, \mathbf{Z n O} 4)$ were not analysed by TEM.

\subsection{UV-vis spectra}

The UV reflection/absorption or emission techniques have conventionally been used to measure the electronic core levels in solids, basically measuring the energy difference by inducing transitions between electronic levels or by exciting collective modes. ${ }^{9}$

The properties of the $\mathrm{ZnO}$ nanoparticles depend closely on their particle size, morphology, surface area and activity, the nanoparticles exhibiting novel properties due to quantum confinement effects compared with their bulk properties. The quantum confinement of $\mathrm{ZnO}$ nanoparticles can be illustrated from the shift of the optical absorption edge to higher energies with decreasing size. ${ }^{29}$

In order to analyse the optical properties of the $\mathrm{ZnO}$ thin films, the optical reflectance spectra were obtained. The absorbance spectra of the films are shown in figure 3 .

For the opaque $\mathrm{ZnO}$ films the absorption spectra are similar, with an absorption band at $331 \mathrm{~nm}$ for $\mathbf{Z n O} \mathbf{1}$ and at 330 for $\mathbf{Z n O ~ 2 . ~ T h e ~ a b s o r p t i o n ~ b a n d s ~ a r e ~ m o v e d ~ t o ~ U V ~ d o m a i n ~}$ (blue-shift) compared with commercial bulk $\mathrm{ZnO}(354 \mathrm{~nm}){ }^{9}$
The are two explanation, for the movement of bands, namely (i) the doping of $\mathrm{ZnO}$ by $\mathrm{Al}$ and (ii) the influence of the particles mean diameter, smaller diameter meaning lower wavelength. The blue-shift of the absorption edge of Al-doped nanocrystalline films may be attributed to the poor crystallinity of the films and also to increase in disorder with Al doping. ${ }^{30}$ The transformation of AZO powder in thin film has not significantly modified the position of absorption band.

It can also be seen that the absorption profiles for the ZnO 1 and $\mathrm{ZnO} 2$ are a little different from those of the samples AZO, ZnO 3 and $\mathbf{Z n O} 4$. It is a continuous absorption for $\mathrm{ZnO} 1$ and $\mathrm{ZnO}$ 2, from the initial wavelength of 850 $\mathrm{nm}$ to the absorption edges, behaviour that was revealed for nanotubes and nanorods, whereas for the $\mathbf{A Z O}, \mathbf{Z n O} 3$ and ZnO 4 particles, there is only a slight absorption from 850 $\mathrm{nm}$ to the absorption edge, the behaviour being assigned to spherical particles. ${ }^{31}$

For the transparent films $(\mathbf{Z n O ~ 3 , ~ Z n O ~ 4 ) ~ t h e ~ b a n d s ~}$ assigned to $\mathrm{ZnO}$ are overlapped with other bands, being found only shoulders $350 \mathrm{~nm}$ (355 nm for ZnO 3, $357 \mathrm{~nm}$

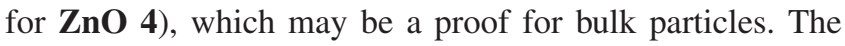
presence of absorption maxima at lower wavelengths may be also attributed to the poor crystallinity of the films and the other bands may be assigned to the environment or to 
a
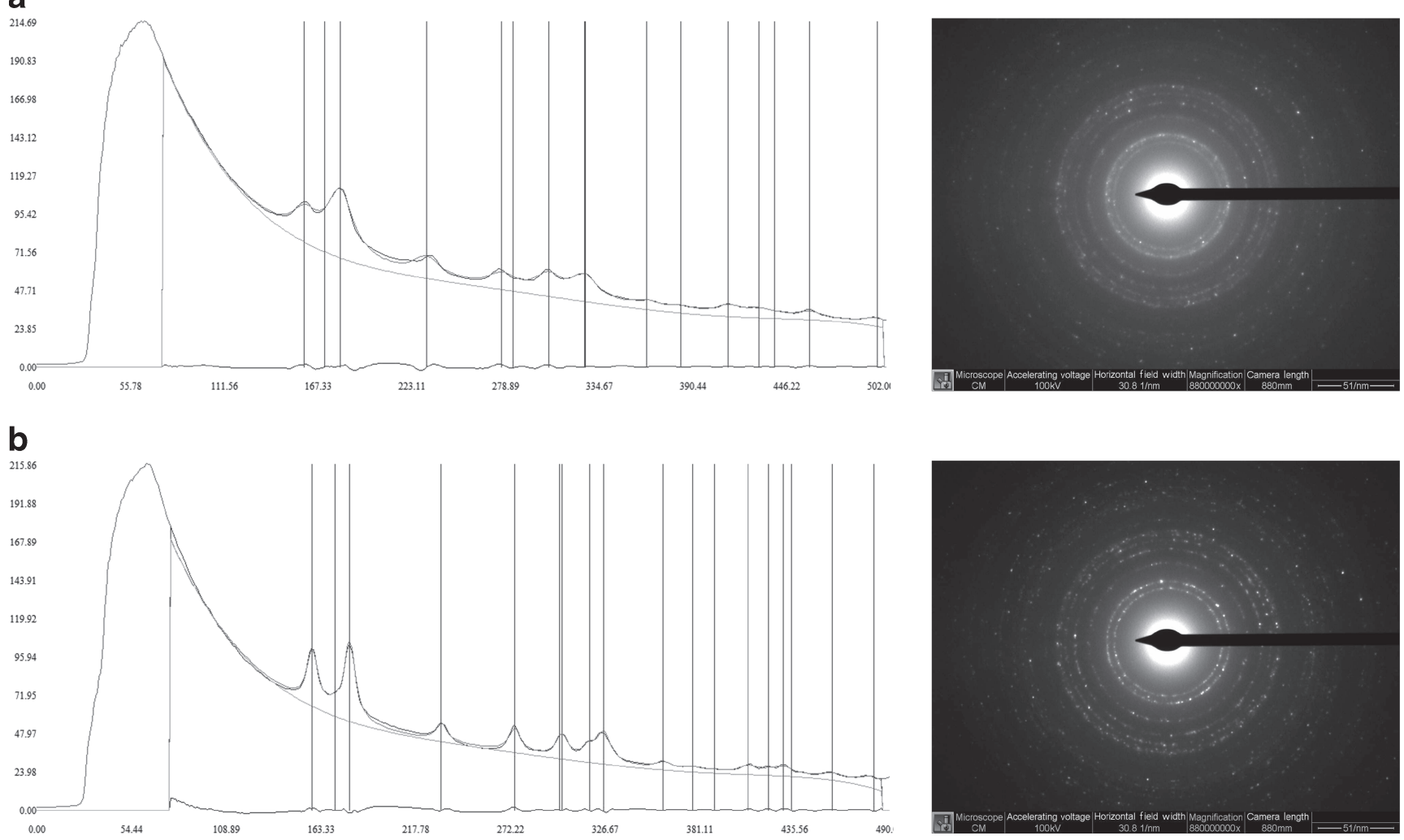

Figure 2. The SAED patterns (right) and the intensity distribution (arbitrary units) depending on $R=\lambda / 2 \sin \theta$, for (a) ZnO $\mathbf{1}$ and (b) ZnO 2 samples.

Table 1. The lattice parameters for $\mathrm{ZnO} 1$ and $\mathrm{ZnO} 2$.

\begin{tabular}{llll}
\hline Sample & $a(\AA)$ & $c(\AA)$ & $c / a$ \\
\hline ZnO 1 & 3.2048 & 5.1324 & 1.601473 \\
ZnO 2 & 3.2571 & 5.2162 & 1.601486 \\
\hline
\end{tabular}

substrate (soda lime glass with a conductive layer of F-doped $\mathrm{SnO}_{2}$ ) on which $\mathrm{ZnO}$ films were deposited, having in view the transparency of film.

\subsection{Bandgap energies}

The bandgap of semiconductor materials plays a fundamental role in their electrical and optical properties, being important and necessary to study on the bandgap change in order to gain a better understanding for their relevant properties. For nanosized semiconductors, the bandgap displays blueshift with decreasing the size because of surface skin quantum trapping. ${ }^{32,33}$

As $\mathrm{ZnO}$ is considered a direct bandgap semiconductor, we can use the Tauc relation ${ }^{34}$ to estimate the optical bandgap $\left(E_{\mathrm{g}}\right)$ :

$$
\alpha h v=C\left(h v-E_{\mathrm{g}}\right)^{n},
$$

where $\alpha$ is the absorption coefficient of the $\mathrm{ZnO}$ at a certain value of wavelength $\lambda, h$ Planck's constant, $C$ the proportionality constant, $v$ the frequency of light and $n=1 / 2$ (for direct transition mode materials).

The absorption coefficient is evaluated using the relation

$$
\alpha=k \ln \left(\frac{R_{\max }-R_{\min }}{R-R_{\min }}\right),
$$

where $k$ is a constant, $R_{\max }$ the maximum reflectance and $R_{\text {min }}$ the minimum reflectance.

Consideration of Eqs. (1) and (2) gives Eq. (3)

$$
(\alpha h v)^{2}=C^{\prime}\left(h v-E_{\mathrm{g}}\right),
$$

where $C^{\prime}$ is a constant. From Eq. (3), a Tauc plot can be drawn of $(\alpha h v)^{2} v s . h v$. The point of the extrapolation of the linear part that meets the abscissa will give the value of the bandgap energy of the material. ${ }^{4,34,35}$

Figure 4 shows the Tauc plots for $\mathrm{ZnO}$ samples. The values obtained for the bandgap energies (AZO, $3.49 \mathrm{eV}$; ZnO 1, $3.58 \mathrm{eV}$; $\mathbf{Z n O} 23.59 \mathrm{eV}$ ) correspond to the UV region of the electromagnetic spectrum.

The experimental results indicate that the AZO nanopowder has a wider bandgap compared to that of the bigger sized spherical crystals $(3.34 \mathrm{eV}){ }^{9}$ Also, the bandgap energy for Al-doped $\mathrm{ZnO}$ is larger than that of the bulk $\mathrm{ZnO}$, which is believed to be Burstein-Moss effect because of the 


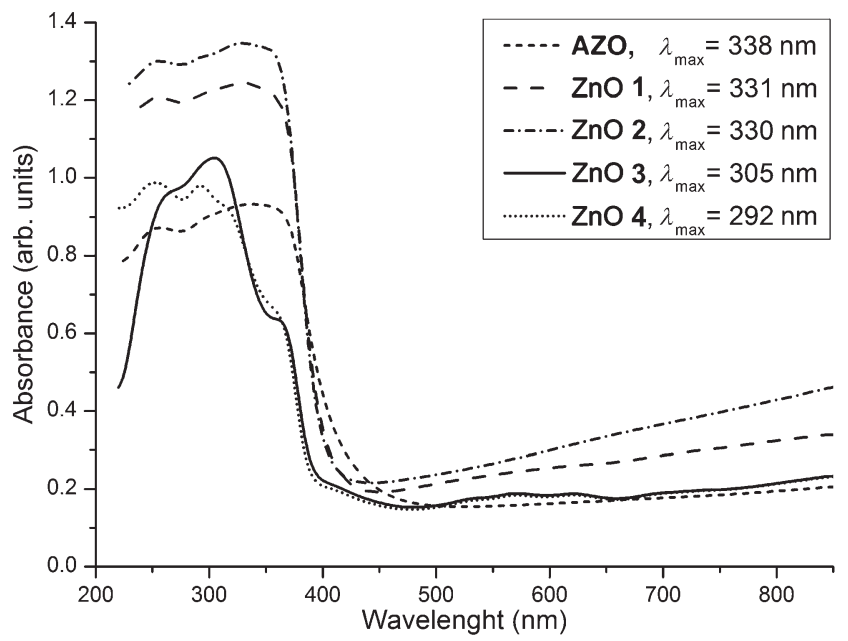

Figure 3. UV-vis absorption spectra of $\mathrm{AZO}$ powder and $\mathrm{ZnO}$ films.

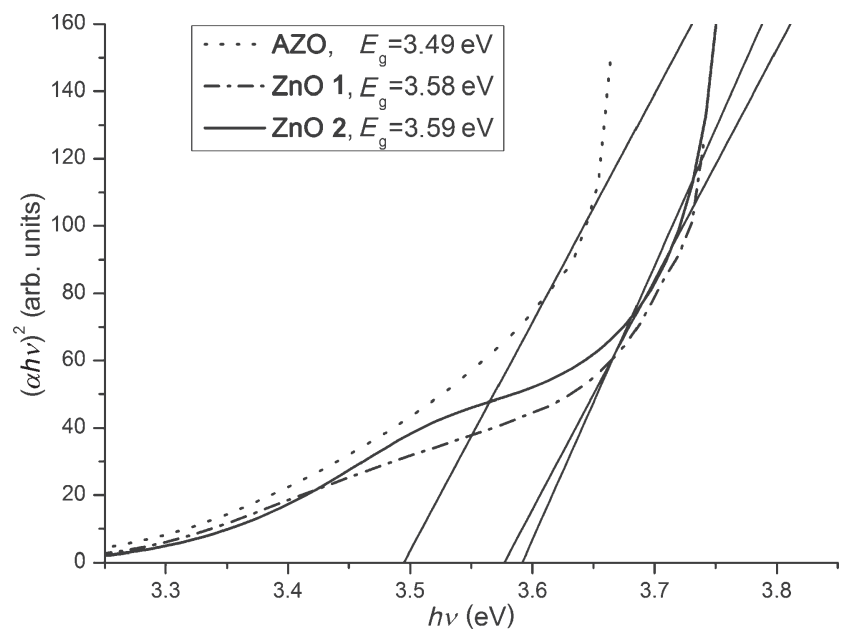

Figure 4. Tauc plots $\left((\alpha h v)^{2} v s\right.$. photon energy) for $\mathrm{ZnO}$ samples.

doping by $\mathrm{Al}$. $\mathrm{ZnO}$ is naturally $n$-type material, and the Fermi level will be inside of the conduction band when it is doped with Al. The results are comparable with those obtained by other researchers; thus, the optical bandgap of Al-doped $\mathrm{ZnO}$ thin films may range from 3.32 to $3.77 \mathrm{eV}^{36}$ or from 3.6 to $3.88 \mathrm{eV}^{37}$

The highest efficient UV emission near band edge may be attributed to free exciton emission with high electronic density of states, which shift to higher energies as the nanoparticles size increase; this variation overlaps with the presence of $\mathrm{Al}(\mathrm{III})$ in $\mathrm{ZnO}$ lattice and the overall result was almost the same value for bandgap energy of ZnO 1 and ZnO 2. The energy gap for $\mathbf{Z n O} \mathbf{1}$ film is higher compared with the precursor (AZO nanopowder), the result being consistent with that obtained for undoped $\mathrm{ZnO} .{ }^{17}$ The results are in good agreement with theoretical estimations, knowing ${ }^{31}$ that at the nanoscale there is an increase in pressure which results in strong forces towards the interior of the crystallites.
Table 2. Typical values of the short circuit current $\left(I_{\mathrm{sc}}\right)$ for an active area of $0.785 \mathrm{~cm}^{2}$, open circuit voltage $(V)$, fill factor (FF) and photovoltaic conversion efficiency $(\eta)$, determined for solar cells fabricated with ZnO sensitized with N719 pigment.

\begin{tabular}{lcccc}
\hline Semiconductor & $I_{\mathrm{sc}}(\mathrm{mA})$ & $V(\mathrm{mV})$ & FF & $\eta(\%)$ \\
\hline ZnO 1 & 2.85 & 395 & 0.372 & 0.5338 \\
ZnO 2 & 0.366 & 518 & 0.479 & 0.1158 \\
ZnO 3 & 0.300 & 460 & 0.240 & 0.0423 \\
ZnO 4 & 0.640 & 520 & 0.287 & 0.1217 \\
\hline
\end{tabular}
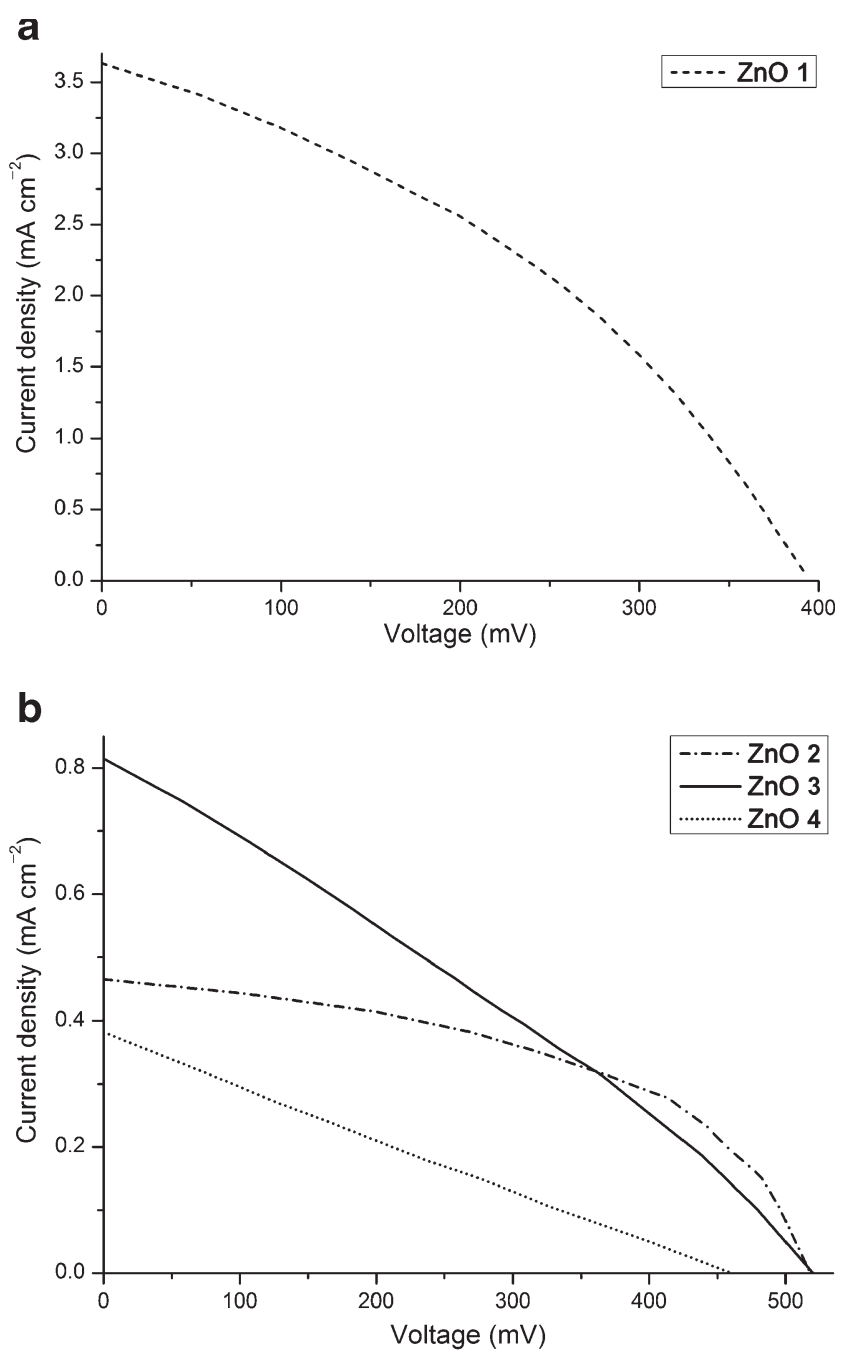

Figure 5. Current-voltage curves of DSSCs fabricated using $\mathrm{ZnO}$ samples: (a) $\mathrm{ZnO} 1$ and (b) $\mathrm{ZnO} \mathrm{2,3}$ and 4.

Therefore, the $\mathrm{ZnO}$ thin films with different morphologies have slightly different light absorption characteristics and may be used in the applications of $\mathrm{ZnO}$, like as semiconductor for solar cells, in order to improve the performance of the cells.

\subsection{The characterization of DSSCs}

Although $\mathrm{ZnO}$ is a very promising semiconductor for DSSCs, the results obtained for ZnO-based DSSCs are still 
lower compared with $\mathrm{TiO}_{2}$-based DSSCs, and one explanation may be the low chemical stability of $\mathrm{ZnO} .{ }^{10,11}$ Due to the presence of carboxyl protons, however, N719 solutions are acidic and may dissolve $\mathrm{ZnO}$ surfaces during the operation of dye loading. ${ }^{32}$ The resulting $\mathrm{Zn}$ (II) ions form insoluble complexes with the N719 dye, causing precipitation of these complexes in the pores of the film. This gives rise to a filter effect (inactive dye molecules), so that net yield for charge carrier injection is decreased, whereas the light-harvesting efficiency is increased during the sensitization process due to the large number of dye molecules in the film. ${ }^{11}$

The typical values resulting from the electro-optical measurements performed on $\mathrm{ZnO}$-based DSSCs fabricated with N719 pigment are displayed in detail in table 2 and illustrated as $I-V$ curves in figure 5 .

Despite the particles mean diameter for $\mathbf{Z n O} \mathbf{1}$ and $\mathbf{Z n O}$ 2, samples are comparable and the band gap energy is almost the same, the values for fill factors and efficiencies are significantly different. This observation highlights the importance of other factors for the performance of DSSC. One of them may be the porosity of the layer and it is expected a low porosity for the layer obtained by electrolysis, which is continuous and compact.

In similar conditions, higher values for efficiency (1.0112 and $1.1940 \%$ ) were obtained using capped $\mathrm{ZnO}$ nanopowders, having comparable values for mean diameter of particles and for bandgap energy as ZnO 1. One explanation for this difference may be the higher surface area and a better porosity, resulted by losing of capping agents. ${ }^{17}$

The very low values of fill factors and also of efficiencies for DSSCs based on ZnO 3 and ZnO 4 make these cells uncompetitive. One explanation of those very low values, and also for the differences between $\mathbf{Z n O ~ 3 -}$ and $\mathbf{Z n O}$ 4-based DSSCs and other cells may be due to the structure of $\mathrm{ZnO}$ films and the adherence to the substrate. The depositing of $\mathrm{ZnO}$ by this spin coating method involves the utilization of solvents like water and ethanol, which are lost during the thermal treatment of plates. This procedure may lead to a non-uniform structure of the film, rather to a mesoporous one. The pores may be visible, voluminous and may influence the continuity of the compact film. The pores dimension may be correlated with the nature of solvent. On the other hand, the proposed spin coating technique was previously used for microscope glass substrates, ${ }^{5}$ thus highlighting the importance of the nature of substrate for the film deposition. $^{15}$

\section{Conclusions}

The experimental results confirmed the importance of the layer deposition method on the properties of semiconductor and on the performances of ZnO-based DSSCs.

The higher value for the DSSC efficiency was achieved for the cell based on ZnO 1 film, which was obtained using AZO nanopowder. This result was in concordance with the mean diameter value, which is smallest for $\mathbf{Z n O} 1$ particles.
However, the difference between $\mathrm{ZnO} 1$ and $\mathrm{ZnO} 2$ may be correlated with other properties of $\mathrm{ZnO}$ layer, like the porosity. The dependence of bandgap energy on the particles dimension and the presence of $\mathrm{Al}$ are not obviously in the comparison between $\mathbf{Z n O} 1$ and $\mathbf{Z n O} 2$, characterized by very close values of the bandgap energy (around $3.60 \mathrm{eV}$ ).

The doctor-blading technique provides the highest value for the DSSC efficiency, but the electrolysis has the advantage of a high fill factor. The efficiency for DSSCs based on $\mathrm{ZnO}$ deposed by the spin coating technique depends on the solvent nature, being highest for more volatile ethanol.

\section{References}

1. O'Regan B and Grätzel M 1991 Nature 353737

2. Nazeeruddin Md K, Baranoff E and Grätzel M 2011 Solar Energy 851178

3. Grätzel M 2003 J. Photochem. Photobiol. C: Photochem. Rev. 4145

4. Pearton S J, Norton D J, Ip K, Heo Y W and Steiner T 2005 Prog. Mater. Sci. 50293

5. Caglar M, Ilican S, Caglar Y and Yakuphanoglu F 2009 Appl. Surf. Sci. 2554491

6. Marczak R, Werner F, Ahmad R, Lobaz V, Guldi D M and Peukert W 2011 Langmuir 273920

7. Özgür Ü, Alivov Y I, Liu C, Teke A, Reshchikov M A, Dogan S, Avrutin V, Cho S J and Morkoç H 2005 J. Appl. Phys. 98041301

8. Baruah S and Dutta J 2009 Sci. Technol. Adv. Mater. 10013001

9. Morkoç H and Özgür Ü 2009 Zinc oxide: fundamentals, materials and device technology (Weinheim: Wiley-VCH Verlag)

10. Gonzalez-Valls I and Lira-Cantu M 2009 Energy Environ. Sci. 219

11. Hagfeldt A, Boschloo G, Sun L, Kloo L and Pettersson H 2010 Chem. Rev. 1106595

12. Mondal S, Bhattacharyya S R and Mitra P 2013 Pramana - J. Phys. 80315

13. Huang D, Zeng X, Zheng Y, Wang X and Yang Y 2013 Front. Optoelectron. 6114

14. Tewari S and Bhattacharjee A 2011 Pramana - J. Phys. 76153

15. Mane R S and Lokhande C D 2000 Mater. Chem. Phys. 651

16. Dumbrava A, Jurca B, Ciupina V, Segal E and Brezeanu M 2005 J. Therm. Anal. Cal. 79509

17. Dumbrava A, Prodan G and Moscalu F 2013 Mater. Sci. Semicond. Process. 161095

18. Saito M and Fujihara S 2008 Energy Environ. Sci. 1280

19. Chae K W, Zhang Q, Kim J S, Jeong Y H and Cao G 2010 Beilstein J. Nanotechnol. 1128

20. Aslan M H, Oral A Y, Menşur E, Gl A and Başaran E 2004 Sol. Energy Mater. Sol. Cells $\mathbf{8 2} 543$

21. Longo C and De Paoli M A 2003 J. Braz. Chem. Soc. 14889

22. Smestad G P 1998 Sol. Energy Mater. Sol. Cells 55157

23. Oprea C I, Dumbrava A, Enache I, Lungu J, Georgescu A, Moscalu F, Oprea C and Girtu M A 2011 Phys. Status Solidi A 2082467 
24. Oprea C I, Dumbrava A, Enache I, Georgescu A and Girtu M A 2012 J. Photochem. Photobiol. A: Chem. 2405

25. Dumbrava A, Enache I, Oprea C I, Georgescu A and Girtu M A 2012 Digest J. Nanomater. Bios. 7339

26. Georgescu A, Damache G and Gîrţu M A 2008 J. Optoelectron. Adv. Mater. 103003

27. Hou Y, Yang M, Pang G and Feng S 2008 J. Mater. Sci. 43 2149

28. Toby B H 2006 Powder Diffract. 2167

29. Tan S T, Chen B J, Sun X W and Fan W J 2005 J. Appl. Phys. 98013505

30. Patil S L, Chougule M A, Pawar S G, Raut B T, Sen S and Patil V B 2011 J. Alloys Compd. 50910055
31. Lyu S C, Zhang Y, Ruh H, Lee H J, Shim H W, Suh E K and Lee C J 2002 Chem. Phys. Lett. 363134

32. Lin K F, Cheng H M, Hsu H C, Lin L J and Hsieh W F 2005 Chem. Phys. Lett. 409208

33. Wang Y, Ouyang G, Wang L L, Tang L M, Tang D S and Sun C Q 2008 Chem. Phys. Lett. 463383

34. Tauc J, Grigorovici R and Vancu A 1966 Phys. Status Solidi B 15627

35. Rusdi R, Rahman A A, Mohamed N S, Kamarudin N and Kamarulzaman N 2011 Powder Technol. 21018

36. Shan F K and Yu Y S 2004 J. Eur. Ceram. Soc. 241869

37. Jung Y S, Choi H W and Kim K H 2009 J. Korean Phys. Soc. $\mathbf{5 5} 1945$ 